\title{
Possíveis leituras de extensões da arte nas ilustrações de livros: a Pós-Produção nas imagens de Rébecca Dautremer
}

\author{
Anelise Zimmermann ${ }^{1}$ \\ Universidade do Estado de Santa Catarina
}

\section{Resumo}

Nesse artigo é apresentada uma proposta de leitura de imagens a partir do livro ilustrado associada à leitura de manifestações artísticas, com foco na formação visual na escola. É tomado como instrumento de leitura o modelo desenvolvido por Ramalho e Oliveira (2005). Este modelo parte da Semiótica Greimasiana e baseia-se na desconstrução e reelaboração das imagens e na exploração de suas significações. Como forma de experimentação desta proposta é apresentado um breve exercício de leitura de ilustrações do livro Diario Segreto di Pollicino (2010), de Rébecca Dautremer, relacionadas à perspectiva da Arte na PósProdução segundo características levantadas por Bourriaud (2009).

Palavras-Chave: Livro llustrado. Leitura de imagens. Pós-Produção

\begin{abstract}
Herein we present a proposal to read images from illustrated books associated with the reading of artistic manifestations, focusing on visual training at school. It is taken as a tool for reading the model developed by Ramalho and Oliveira (2005), which is based on Greimas Semiotics by deconstructing and re-elaborating images to and explore its meanings. As a way of testing this proposal, we propose a short exercise to read illustrations from Rebecca Dautremer's Diario Segreto di Pollicino (2010), related to the perspective of Art in Post-Production, according to characteristics raised by Bourriaud (2009).
\end{abstract}

Keywords: Picturebook. Picture reading. Post-production.

\footnotetext{
${ }^{1}$ Professora do Departamento de Design da Universidade do Estado de Santa Catarina.
} 


\section{Introdução}

Vivendo em meio ao que Calvino (1990) preconizou como o Milênio da Visibilidade, envolvidos pelo "dilúvio das imagens pré-fabricadas", somos alertados: "Em nossa memória se depositam, por estratos sucessivos, mil estilhaços de imagens, semelhantes a um depósito de lixo, onde é cada vez menos provável que uma delas adquira relevo". (Ibid., p. 107). A partir de outra perspectiva Bourriaud (2009) chama a atenção para o fato de que "não estamos saturados de imagens; estamos submetidos à escassez de certas imagens" (2009, p. 59). Segundo Bourriaud (Ibid.) cabe à arte contemporânea a elaboração de imagens que despertem o observador para novos enredos e leituras do mundo que o cerca; imagens estas que se oponham, que proponham, que desconstruam e revelem múltiplas combinações, envolvendo, provocando e convocando seu leitor a sua reelaboração. Ramalho e Oliveira (2005), entretanto, destaca o fato de que essa participação do observador, de fato ativa, só é possível quando este possui os recursos mínimos para uma leitura crítica das imagens, podendo assim ultrapassar os níveis superficiais das significações.

É neste contexto que encontram-se os livros ilustrados, livros compostos por textos verbais e visuais que, em conjunto, propõem uma história. Estes livros, geralmente associados ao público infantil, muitas vezes são abandonados tão logo a alfabetização verbal é considerada completa, ignorando possíveis participações das ilustrações na elaboração das histórias, como que sendo desnecessárias. Entretanto, a ilustradora Dautremer ao falar sobre seu trabalho comenta: "Com minhas ilustrações tento construir uma história que não é redundante ao texto. [...] Tento oferecer uma outra perspectiva sobre a aventura, levar o leitor a um caminho paralelo que irá enriquecer a sua leitura e abrir outras portas. (DAUTREMER, 2010, p. 01, tradução nossa). Ignorando tais possibilidades das ilustrações pais e professores muitas vezes esquecem da importância da aprendizagem e exercício da leitura visual e sua participação na elaboração das mensagens. Com base em tais aspectos neste artigo são discutidos os conceitos de "livro infantil" e "livro ilustrado", bem como questões referentes ao seu público e formas frequentes de leitura.

Em seguida, considerando a importância da leitura visual e sua instrumentalização, é sugerida uma proposta de atividade de leitura de imagens por meio de ilustrações de livros e sua aproximação com o ensino da arte. Partindo de estudos anteriores (ZIMMERMANN; RAMALHO e OLIVEIRA, 2007), sugere-se a utilização do modelo de leitura de imagens proposto pela pesquisa de Ramalho e Oliveira (2005), o qual tem como base a Semiótica 
Greimasiana. Este modelo pode ser aplicado aos mais variados tipos de imagens, de forma bastante didática e clara, portanto também na escola com as mais variadas faixas etárias, tanto na leitura do livro ilustrado quanto na leitura de produções artísticas.

Como exemplo de leitura de imagens são analisados aspectos estéticos e narrativos das ilustrações de Rébecca Dautremer do livro Diario Segreto di Pollicino (LECHERMEIER, 2010), uma adaptação do clássico Pequeno Polegar. A análise é feita a partir da perspectiva da Arte na Pós-Produção segundo características levantadas por Bourriaud (2009). Como fontes de referência à análise foram incluídas à consulta ao Rébecca Dautremer: Artbook (DAUTREMER, 2009), portfólio de sua trajetória profissional e à entrevistas concedidas pela ilustradora a publicações do meio literário.

\section{O livro ilustrado}

Em estudos anteriores (ZIMMERMANN; OLIVEIRA, 2007) foi proposto a utilização de livros ilustrados como recurso para o exercício da leitura visual na escola e sua aproximação com o ensino da arte. Alguns aspectos já levantados merecem ser retomados visto que justificam a continuação da pesquisa sobre o tema. Convém salientar a utilização do termo "livro ilustrado" em substituição ao termo "livro infantil" empregado anteriormente (Ibid.). A este último é frequentemente atribuído o estereótipo de livro exclusivamente para crianças, repleto de imagens extremamente coloridas e decorativas com a função de auxiliar a leitura do texto verbal ${ }^{2}$ àqueles que estão em período de alfabetização. Partindo desse ponto de vista muitos jovens leitores abandonam, e muitos são encorajados a isso, os livros ilustrados a medida que desenvolvem sua leitura verbal, ignorando porém, as possibilidades da leitura visual através dos livros.

A utilização do termo "livro ilustrado", utilizado em traduções de publicações recentes $^{3}$ (LINDEN, 2011a; SCOTT e NIKOLAJEVA, 2011) mas ainda pouco empregado no

\footnotetext{
${ }^{2}$ Considera-se que o termo texto, dentro da perspectiva da semiótica greimasiana refere-se a toda e qualquer estrutura narrativa, seja ela formada por imagens ou palavras. (RAMALHO E OLIVEIRA, 2005).

${ }^{3}$ Estes livros foram originalmente publicados em inglês. Em Livro llustrado: Palavras e imagens (NIKOLAJEVA; SCOTT, 2011) consta em nota de rodapé comentários acerca da tradução do termo empregado "livro ilustrado". "Como no Brasil essa nomenclatura ainda é controversa, optou-se pelas seguintes traduções: picturebook para "livro ilustrado", illustrated book, picture book e books with pictures para "livro com ilustração". Nessas três últimas denominações, a obra exemplificada não apresenta inter-relação explícita entre palavra e imagem. Importante notar que as autoras deste livro distinguem picturebook de picture book, diferentemente de outros teóricos citados ao longo da obra." [Nota dos editores]. (Ibid., p. 13)
} 
Brasil, parece mais adequada a esse estudo pois considera que livros com ilustrações não se destinam exclusivamente ao público infantil, podendo falar a leitores de idades variadas.

Um aspecto interessante quanto a este assunto é levantado por Linden (2011b, p. 01), segundo a qual a leitura do livro ilustrado é muitas vezes uma leitura "partilhada", ou seja, feita conjuntamente por pais e filhos, também chamada de "dupla audiência" (NIKOLAJEVA; SCOTT, 2011). Tal fato exige que o livro desperte o interesse destes diferentes leitores, explorando o diálogo entre o texto verbal e o texto visual a partir de diferentes camadas de significações.

\begin{abstract}
O leitor transita entre o verbal e o visual, em uma concatenação sempre expansiva do entendimento. Cada nova leitura, tanto de palavras como de imagens, cria pré-requisitos melhores para uma interpretação mais adequada do todo. Presume-se que as crianças sabem disso por intuição quando pedem que o mesmo livro seja lido para elas em voz alta repetidas vezes. Na verdade, elas não leem o mesmo livro; elas penetram cada vez mais fundo em seu significado. É muito comum os adultos perderem a capacidade de ler os livros ilustrados dessa maneira, porque ignoram o todo e encaram as ilustrações como meramente decorativas. (NIKOLAJEVA; SCOTT, 2011, p. 14)
\end{abstract}

Muitas vezes, em uma leitura partilhada, a criança percebe detalhes na história completamente ignorados pelo adulto, pois enquanto este concentra-se na leitura do texto verbal, a criança percebe o conjunto do texto verbal - texto visual (LINDEN, 2011b). Também de um modo geral a criança se permite observar com mais atenção às ilustrações, procurando pistas que possam estar escondidas, ora girando o livro de ponta-cabeça, ora alterando a sequência das páginas, subvertendo a linearidade da história.

Hans Christian Andersen (1805-1875), escritor considerado um dos precursores da literatura infantil, já trabalhava com a ideia da leitura "partilhada", identificando as possibilidades e dificuldades de compreensão desse gênero literário pelo público adulto. Segundo anotações feitas em um diário pessoal, Andersen teria ficado irritado com uma estátua criada em sua homenagem pelo fato de ser representado rodeado por crianças: "Eu disse [...] que os meus contos eram tanto para os adultos quanto para as crianças, e que estas últimas compreendiam somente as personagens secundárias, e que só as pessoas maduras viam e compreendiam tudo." (ANDERSEN, 2004, p. 18). Andersen também comenta sobre esse mesmo assunto em uma carta escrita a seu amigo Ingemann: "'Pego uma ideia para adultos e a conto às crianças, sempre me lembrando de que o pai e a mãe geralmente a escutam e que é preciso dar-Ihes assunto sobre o qual pensar". (Ibid., p. 18) 
Essa barreira, entre o infantil e o adulto, tem gerado muitos questionamentos sobre os limites os definem. Um exemplo são as diferentes reações provocadas pelo livro Where the wild things are (1963), escrito e ilustrado por Maurice Sendak (1928 - 2012). O livro, logo após sua primeira publicação, recebeu diversos prêmios literários, entre estes o Caldecott Medal (1964), justamente por quebrar paradigmas do gênero da literatura infantil. Entretanto, nos primeiros anos após seu lançamento, este mesmo livro foi fortemente proibido nas bibliotecas americanas, bem como sua venda em países da América Latina (BALDASSARRO, 2011). Às objeções à obra iam desde o comportamento de seus personagens, considerados em alguns momentos "inadequados", podendo afetar de forma prejudicial o comportamento de seus leitores ${ }^{4}$, até às características estéticas das ilustrações, acusadas de "escuras e sombrias", podendo ser relacionadas à bruxaria e elementos sobrenaturais.

Também a ilustradora contemporânea Dautremer (1971- ) tem suas ilustrações muitas vezes classificadas como "sombrias", "melancólicas" e "sinistras" (DAUTREMER, 2013). Falando sobre o assunto, Dautremer comenta: "Não vejo por que não falar de melancolia para as crianças. Eu não me coloco impedimento algum de falar disso, é meu gosto pessoal." (Ibid., p. 01). Quanto à relação de suas ilustrações com seu público Dautremer diz: "Não penso especificamente nas crianças quando trabalho, penso em pessoas de todas as idades. De fato, muitos dos meus livros são comprados por adultos." (DAUTREMER, 2011, p. 01). Reafirmando essa ideia, Dautremer ainda comenta: "Minhas imagens são ilustrações claras, legíveis e de fácil compreensão, a partir daí cada um faz o que quer com estas imagens. Eu não digo 'Ei, eu trabalho para as crianças.' Não mesmo. Eu não ponho barreira entre pais e filhos. Crio imagens para pessoas ..."

Entretanto, no meio literário de uma forma geral, as barreiras ou o estranhamento entre o adulto e o infantil existem e não parecem bem resolvidas ${ }^{5}$. Em outras áreas, como por exemplo no mercado cinematográfico, há tempos foram identificadas as possibilidades da leitura partilhada entre crianças e adultos, investindo-se cada vez mais nas produções de animações, lotando salas de cinema com públicos das mais variadas idades.

\footnotetext{
4 "Um menino jogando uma garrafa foi considerado um comportamento perigoso e Sendak foi acusado de glorificar a raiva de Max [personagem principal], o que levou os psicólogos a condená-lo como "muito escuro e assustador." Em março de 1969, na coluna para mulheres do 'Home Journal, o psicólogo infantil Bruno Bettelheim chamou o livro psicologicamente prejudicial para crianças de 3 a 4 anos. Segundo ele, a idéia de uma mãe privar uma criança de alimentos era uma forma inadequada de punição, podendo traumatizar os jovens leitores." (BALDASSARRO, 2011, p. 01)

${ }^{5}$ Convém salientar que o conceito de infância está em constante transformação (ARIĖS, 1981), interferindo, com isso, no que pode ser considerado infantil ou não, e mesmo adequado à criança.
} 


\section{O livro ilustrado e suas possíveis leituras na escola}

Recuperando argumentos anteriores (ZIMMERMANN; OLIVEIRA, 2007), é interessante mencionar fatores relevantes à escolha do artefato "livro ilustrado" para compor exercícios de leitura visual e suas possíveis relações com o ensino da arte na escola. Convém lembrar que o livro, por suas características físicas, possibilita a leitura individual ou coletiva, respeitando o ritmo de seus leitores, permitindo que detalhes sejam retomados com facilidade, por meio do manuseio simples. Além disso, o livro já está presente na escola, sendo assim um recurso de fácil acesso ao professor, dispensando a necessidade de reproduções ou adequações. Embora sendo um múltiplo, assim como a gravura, o livro é uma reprodução elaborada para ser assim visualizada por seu público, não passando por nenhum processo de distorção além de seu próprio processo de produção ${ }^{6}$.

No que se refere a possíveis relações entre as ilustrações de livros ilustrados e produções artísticas é inegável a presença das artes no repertório visual de muitos ilustradores, a qual transparece em suas imagens, tanto por seus aspectos técnicos, como narrativos, resgatando ora referências do passado, ora indicando características contemporâneas (Ibid.). A ilustradora Dautremer, por exemplo, busca referências imagéticas de pintores do século XVI e XVII, entre eles Brueghel (cerca de 1525-69), Velázquez (1599 1660), e Vermeer (1632 - 1675) (SOBRINO, 2011, p. 01), assim como de fotógrafos do século XIX, como Julia Margaret Cameron (1815 -1879) ou fotógrafos contemporâneos, entre eles Graciela Iturbide (1942 - ) e Raymond Depardon (1942- ) (CADILHAC, 2010).

A proposta aqui apresentada, concentra-se nas características estéticas e possibilidades narrativas das ilustrações, não aspirando atribuir a estas o caráter de arte ou mesmo aprofundar a essa discussão. Também não se ignora os riscos da chamada didatização da literatura, quando "o livro vira tarefa escolar e não um objeto de prazer" (LINS, 2003, p. 43). O que se propõe, entretanto, é a exploração das possibilidades de leitura dos livros, estabelecendo-se, quando adequado, relações com produções artísticas e repertório visual de seus leitores.

Para tanto sugere-se o uso da semiótica discursiva e sua vertente derivada dos estudos de Algirdas Julien Greimas, denominada greimasiana, especificamente o modelo

\footnotetext{
${ }^{6}$ No caso dos livros ilustrados, mesmo existindo o "original", ou seja, a ilustração original, esta é concebida para ser reproduzida considerando os aspectos técnicos dessa reprodução.
} 
desenvolvido por Ramalho e Oliveira (2005). Tal sugestão deve-se ao fato deste modelo de leitura ser adaptável às mais variadas mídias, imagens ${ }^{7}$ e áreas do conhecimento, podendo ser aplicado a estudos com alunos de faixas etárias variadas, de forma clara e objetiva.

O modelo de leitura de imagens proposto por Ramalho e Oliveira (2005) baseia-se na decomposição da imagem e sua recomposição, indo das significações mais amplas às mais específicas e complexas, em um trânsito entre os elementos. Por meio de procedimentos relacionais buscam-se efeitos de sentido em diferentes camadas de significações que podem muitas vezes passar despercebidos em uma leitura superficial das imagens.

São inúmeras as trilhas que se entrecruzam no visível da imagem (plano de expressão) ao mesmo tempo em que tecem a significação (plano de conteúdo); daí a necessidade de observar minuciosamente toda a imagem, resgatando os pontos mais relevantes para, a partir deles, recriar, traduzindo uma teia de elementos e procedimentos significantes que, como tal, é construída por meio de linhas paralelas, concêntricas, todas relacionadas. (Ibid., p. 53)

A partir dessa prática de leitura é possível que um mesmo livro ilustrado conte diferentes versões de uma história, também permitindo a leitura "partilhada", como já proposto por Andersen (2004). Assim, considera-se que são as experiências do autor, materializadas por meio de sua obra, somadas às experiências do leitor que irão compor a história. Quanto a esses aspectos Ramalho e Oliveira explica:

Em cada texto visual está registrado um discurso, evidenciando uma visão específica de seu criador, ou seja, o modo como o autor da obra vive e vê o mundo também é mostrado na sua criação. A imagem mostra a sua visão de mundo, suas relações com o seu contexto, além de sua capacidade de manipulação do código ao qual pertence a imagem. (RAMALHO e OLIVEIRA, 2005, p. 52)

Vale salientar, contudo, que "tão logo o criador termine o seu trabalho, ele não mais Ihe pertence. A imagem passa a falar por si mesma, independentemente do que seu autor tenha desejado dizer."(Ibid., loc. cit.). Tal argumento remete à fala de Dautremer citada anteriormente, na qual reconhece a participação do leitor ao dizer "Minhas imagens são

\footnotetext{
${ }^{7}$ Imagem: "consideradas toda e qualquer imagem estética produzido pelo homem, seja ela uma obra de arte ou não; incluem-se também, além das manifestações do código visual, aquelas pertencentes ao sistema cênico, musical, audiovisual e mesmo ao verbal. [...] Este conceito abrangente de imagem abarca ainda, sem discriminação, tanto as produções genericamente classificadas como eruditas, quando as de origem popular e, igualmente, as que se destinam à massa populacional, desde produtos industriais até os televisivos. (RAMALHO e OLIVEIRA, 1998, p. 3)
} 
ilustrações claras, legíveis e de fácil compreensão, a partir daí cada um faz o que quer com estas imagens. (DAUTREMER, 2010, p. 01, tradução nossa).

\section{A Pós-Produção nas ilustrações de Dautremer}

Em um exercício de leitura de imagens a partir da desconstrução e reconstrução de ilustrações de Dautremer no livro Diario Segreto di Pollicino (2010), algumas articulações entre sua obra e características da arte contemporânea se revelam. Considerando a amplitude desta leitura, a análise apresentada a seguir concentra-se em apenas alguns aspectos relacionados ao que o filósofo, crítico, editor e curador francês Nicolas Borriaud define como a Arte na Pós-Produção. Também devido à extensão da obra analisada, aproximadamente 200 páginas praticamente todas ilustradas, apenas algumas destas foram selecionadas para compor a análise.

De forma complementar são também feitas referências à publicação "Rébecca Dautremer: Artbook" (2009), que contém parte do portfólio da ilustradora, detalhes de seu processo criativo e supostas cenas de seu cotidiano. Este livro, escrito por Philippe Lechermeier e ilustrado por Rébecca Dautremer, foi originalmente publicado em francês com o título Journal secret du Petit Poucet, traduzido em português como Diário Secreto do Pequeno Polegar. A obra apresenta um reconto do clássico O Pequeno Polegar, uma adaptação de histórias populares do século XVII, escrito pelo francês Charles Perrault (1628 - 1703) e publicado pela primeira vez em 1697. Apesar de a primeira publicação ser também ilustrada, foi na reedição de 1862, chamada "Contes de Perrault" que as ilustrações, feitas por Gustave Doré, ganharam notoriedade. Nessa segunda versão o livro apresenta as dimensões aproximadas de $19,5 \times 24,5 \mathrm{~cm}$, sendo impresso em preto e branco, como as ilustrações reproduzidas através da xilogravura. O conto ocupa aproximadamente trinta e quatro páginas do livro, apresentando 10 ilustrações, sendo que, devido às características dos processos de impressão da época, as ilustrações encontram-se todas em páginas isoladas, não sendo acompanhadas por texto verbal ${ }^{8}$.

Já na versão de Lechermeier e Dautremer o livro apresenta um formato menor, $21 \mathrm{x}$ $18 \mathrm{~cm}$, entretanto é composto por aproximadamente duzentas páginas, o que faz com que diferencie-se do formato usual de livros ilustrados, podendo ser associado ao formato de um pequeno álbum pessoal ou diário, como o próprio título do livro indica: "Diário Secreto do 
Pequeno Polegar". As ilustrações aparecem ora intercaladas ao texto, ora misturadas a ele, em alguns momentos o sobrepondo, interferindo em uma suposta sequência narrativa, e em outros momentos é o texto, em forma de anotações pessoais, que se sobrepõe à ilustração. As técnicas utilizadas na construção das imagens são as mais variadas, passando por algumas consideradas clássicas como a pintura em guache e nanquim, até técnicas mistas, envolvendo a colagem e a fotografia.

Adentrando a características mais específicas de algumas destas ilustração convém previamente rever o que o Bourriaud (2009) define como a arte na Pós-Produção. Segundo ele vivemos hoje um período de "caos cultural", caracterizado pela produção imensurável de imagens e produtos dos mais variados, aos quais somos expostos constantemente. $\mathrm{O}$ acesso às produções do passado nunca foi tão fácil, muitas vezes misturando-se às produções atuais. Em meio a esse cenário surge a figura do $D J$, que se aproveita das produções já existentes para elaborar outras composições, questionando concepções de autoria e novidade.

Baseado nestes e em outros argumentos, Bourriaud propõe uma tipologia para a arte contemporânea, caracterizando-a como a arte da Pós-Produção, da mixagem, do aplique, do enxerto, do sampleamento e do scratching, configurando possibilidades de reprogramação do mundo cotidiano e da arte do passado.

Tal concepção tem direta relação com as possibilidades que as mídias digitais atualmente oferecem, através das quais é possível interferir, alterar, mixar e reprogramar mensagens já veiculadas, concebendo novos enredos. O próprio termo "Pós-Produção" atribuído à arte por Bourriaud é sinal de apropriação, visto ter sido tomado do meio cinematográfico, televisivo e fonográfico. Este denomina o tratamento e a reelaboração de registros por meio de cortes, edições ou efeitos especiais, de forma a construir e reelaborar mensagens. A ele relacionam-se termos como "reprogramar" e "recodificar", também presentes no discurso de Bourriaud.

Dentro dessa perspectiva são caracterizadas muitos obras produzidas principalmente a partir dos anos de 1990, as quais expõem o exagero e a variedade de oferta cultural presentes no cotidiano.

As bases da arte da Pós-Produção tem sua origem com as obras de ready-made de Duchamp: a apropriação de produtos industriais pela arte e seu deslocamento, inserindo-o

\footnotetext{
${ }^{8}$ Inclusive, nas páginas compostas por ilustrações, a impressão foi feita em apenas um dos lados da folha.
} 
em um novo contexto. "Não se trata mais de fabricar um objeto, mas de escolher entre os objetos existentes e utilizar ou modificar o item escolhido segundo uma intenção específica" (Ibid., p.22). A matéria-prima do artista deixa de ser a matéria bruta e passa a ser as mercadorias, incorporando o mercado de consumo à arte. Entre exemplos na Pós-Produção estão as obras de Michel Majerus, nas quais são utilizadas embalagens e imagens publicitárias na construção de grandes painéis.

Retomando as ilustrações de Dautremer, também em muitas delas são utilizadas imagens de embalagens, valendo-se de humor e ironia, como no exemplo da Figura 1. As embalagens são fictícias, porém, apresentam a estética de embalagens reais antigas. A ironia se dá pelo fato de que, a esse ponto da história, Pollicino, o personagem que escreve o diário, fala sobre a escassez de comida que sua família está enfrentando, o que os obriga a comer sopa de pedra todos os dias. A representação desse cenário por meio de rótulos de embalagem é uma escolha da ilustradora, ou seja, não consta no texto.

Visualizada dessa forma, mesmo as sopas de pedra parecem poder se transformar em produtos comerciais, ganhando embalagens nas quais seus "benefícios" são destacados, ironizando, de certa forma, o mercado de consumo onde produtos os mais absurdos, enchem prateleiras e sempre encontram compradores.

As embalagens também aparecem em uma das fotografias de Dautremer com sua família em uma suposta cena de seu cotidiano: o café da manhã, imagem que está presente em seu Artbook (Figura 2). Na fotografia, produtos, embalagens e marcas misturam-se em um cenário de caos e identificação com o consumo contemporâneo.
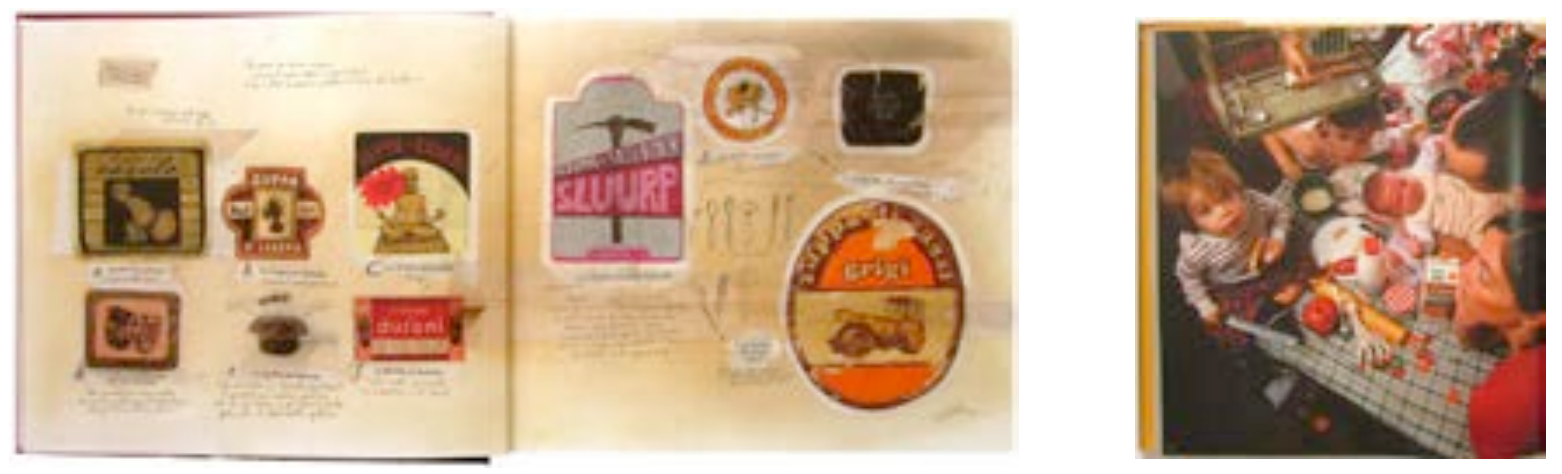

Figura 1: Páginas 19 e 20 do Diario Segreto di Pollicino (LECHERMEIER, 2010)

Figura 2: Página 82 do Rébecca Dautremer: Artbook (DAUTREMER, 2009) 
Dautremer também se apropria da linguagem gráfica utilizada pela indústria para mencionar aspectos da vida do personagem Pollicino. Ao apresentar um manual de montagem de um mobiliário que comporta seis camas empilhadas, Dautremer expõe o fato de que Pollicino mora em uma casa tão pequena e com tantos moradores que seria inviável comportar uma cama para cada um (Figura 3). Em seu Artbook (2009) Dautremer revela referências utilizadas na elaboração dessa ilustração, as quais, de fato, advém de manuais de produtos industriais (Figura 4).
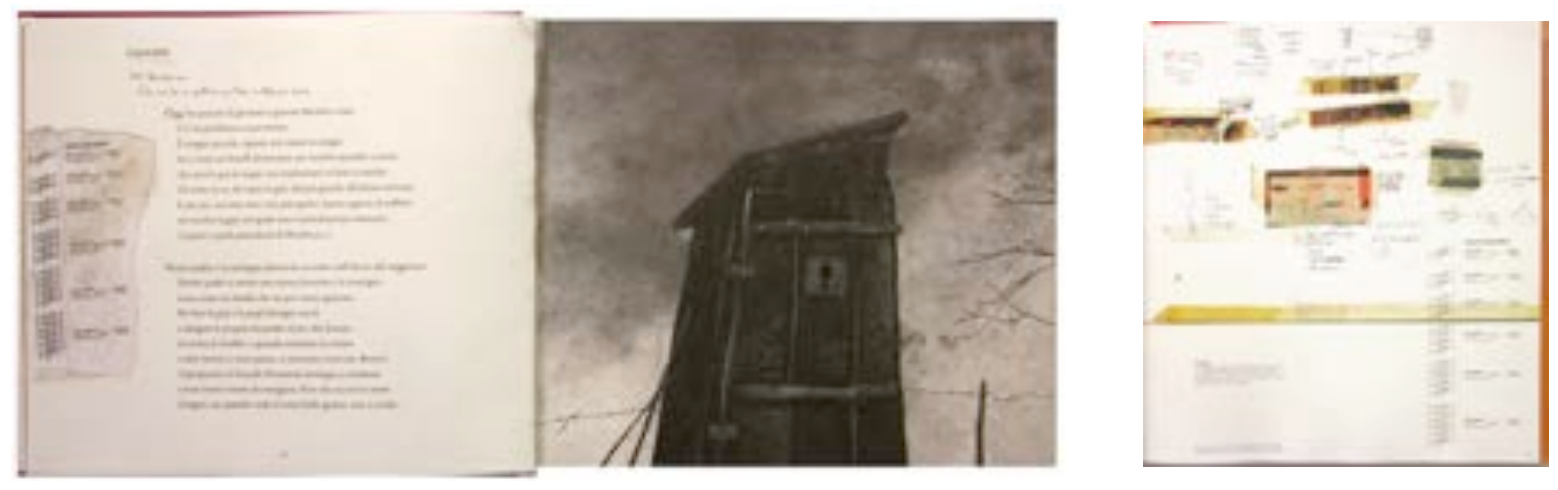

Figura 3: Páginas 16 e 17 do Diario Segreto di Pollicino (LECHERMEIER, 2010)

Figura 4: Página 23 do Rébecca Dautremer: Artbook (DAUTREMER, 2009)

Na arte da Pós-Produção, além da utilização do mercado de consumo como matériaprima, também a produção artística de outras épocas é incorporada à mixagem em novas obras. A Pós-Produção não nega a história da arte, ela a reconfigura. "Trata-se de tomar todos os códigos da cultura, todas as formas concretas da vida cotidiana, todas as obras do patrimônio mundial e colocá-las em funcionamento (....) saber tomar posse e habitá-las" (BOURRIAUD, 2009, p.14). Assim, observam-se em obras contemporâneas traços minimalistas, pop e conceituais, entre outras manifestações.

Da mesma forma, é interessante observar que Dautremer, mesmo na escolha de seus trabalhos, recorre com frequência a referências do passado, tendo ilustrado livros clássicos da literatura infantil, como o Pequeno Polegar e Alice no País das Maravilhas. Também em suas ilustrações Dautremer deixa transparecer a referência a estéticas de diferentes períodos artísticos, ora por meio de imagens surrealistas (Figura 5), ora pela estética da Pop Arte (Figura 6), ora por colagens (Figura 7), todas participando da construção de uma mesma obra. Como já comentado, em entrevista a ilustradora revela 
usar frequentemente como referências as obras de Veemer (por suas cores, luz e sombra); e Brueghel (por suas criaturas fantásticas) (DAUTREMER, 2011).
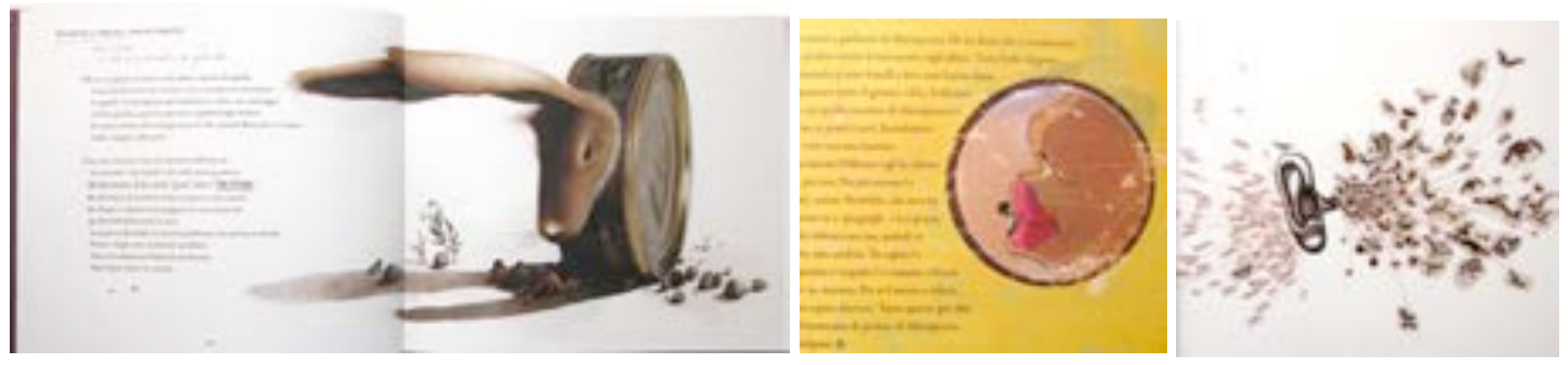

Figure 5: Páginas 100 e 101 do Diario Segreto di Pollicino (LECHERMEIER, 2010) Figure 6: Detalhe da página 45 do Diario Segreto di Pollicino (Ibid.)

Figure 7: Página 51 do Diario Segreto di Pollicino (Ibid.)

Outra característica, presente nas obras da Pós-Produção, é sua relação ou possível comparação a uma feira de usados, nas quais materiais e objetos de variadas proveniências e períodos são reagrupados. Tanto objetos com algum valor histórico, como produtos de caráter efêmero são reciclados a espera de novas funções. "A velha máquina de costura pode se tornar uma mesa de cozinha, um objeto publicitário de 1975 ou um enfeite para a sala" (BOURRIAUD, 2009, p. 27), ou seja, o seu uso não se restringe à finalidade para a qual foi criada. Desde as propostas de ready-made de Duchamp se observa que "utilizar um produto, é, as vezes, trair o seu conceito". (Ibid, p. 21).

Tais aspectos são observados no trabalho de Dautremer, que parece resgatar objetos dos mais variados períodos históricos, inserindo-os em novos contextos. É o que se percebe nas ilustrações das Figuras 8 e 9, imagens que remetem a um tempo passado, com um certo requinte, como uma fotografia antiga envolvida por renda sob um papel de parede (Figura 8) e uma molheira de porcelana com detalhes dourados (Figura 9), as quais dividem espaço com referências atuais e populares, como a imagem de um pictograma de "masculino" na porta de um banheiro rudimentar (Figura 3). Confirmando seu desapego à exatidão das referências, permitindo-se as mais variadas misturas, Dautremer conta: "Não tenho dúvidas em desenhar uma tomada na parede atrás de um personagem com roupas medievais" (SOBRINO, 2011). 

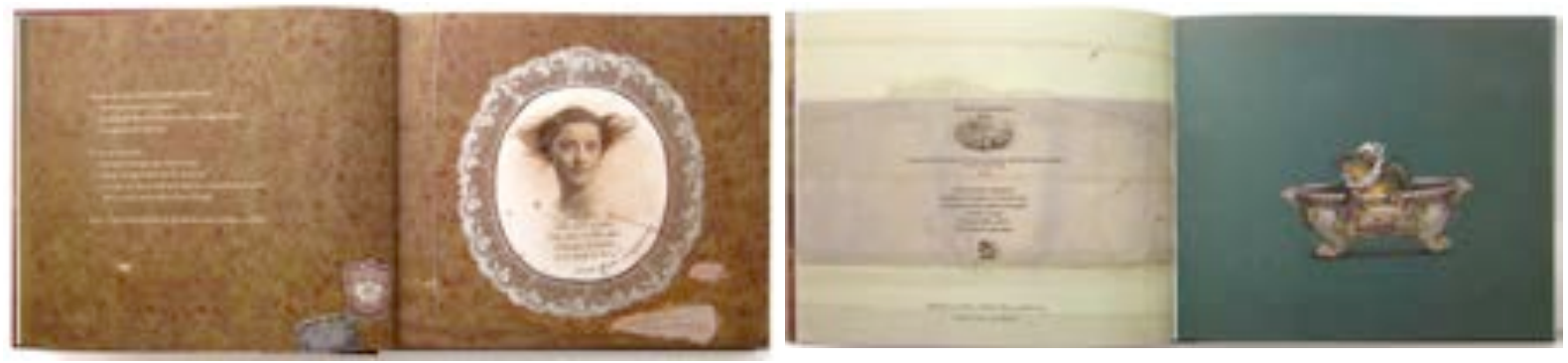

Figure 8: Páginas 24 e 25 do Diario Segreto di Pollicino (LECHERMEIER, 2010) Figure 9: Páginas 112 e 113 do Diario Segreto di Pollicino (Ibid.)

Tomando como outra característica da "feira de usados" muitas obras na PósProdução assumem a estética da disposição aparentemente caótica de produtos, relembrando o caos cultural, o excesso de oferta e o consumismo. Essa forma de exposição não necessariamente assume o caráter de crítica, como observado nos pressupostos da Arte Conceitual, mas aproxima arte ao cotidiano, como parte de um grande "ecossistema cultural" (BOURRIAUD, 2009, p. 48). Esse "caos visual e estético" pode ser observado nas composições das Figuras 10 e 11, nas quais os mais variados estilos de desenho se misturam a colagens de origens também diferenciadas. A variação parece proposital, bem como as sobreposições, as irregularidades, os desencaixes, ou mesmo as rasuras e as manchas no papel, relacionando a história do cotidiano da personagem a uma estética do diário pessoal.
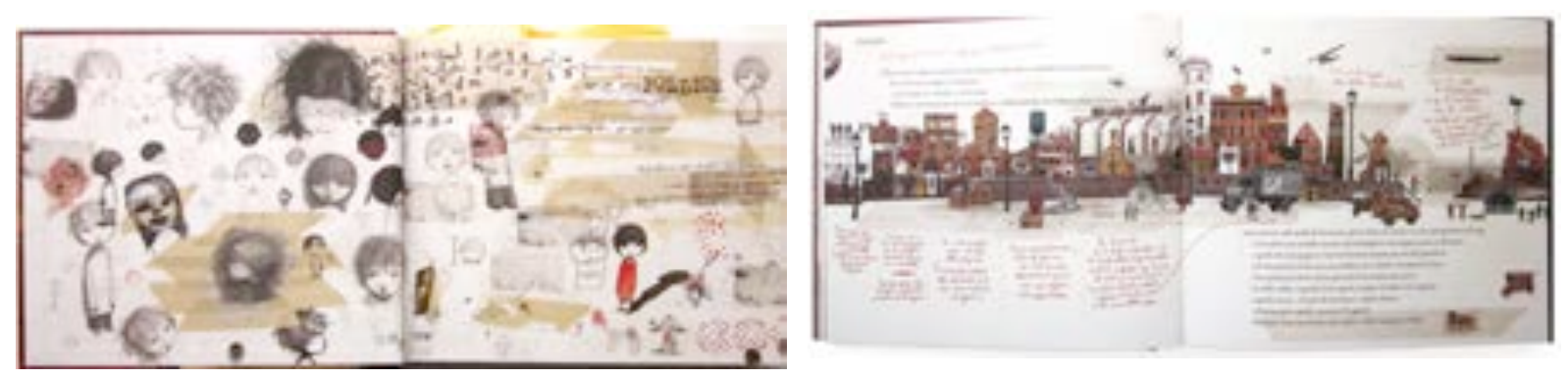

Figure 10: Páginas da guarda inicial do Diario Segreto di Pollicino (LECHERMEIER, 2010) Figure 11: Páginas 68 e 69 do Diario Segreto di Pollicino (Ibid.)

Essa mixagem de várias origens, o aplique, o enxerto, a feira de usados, faz surgir um outro usuário desse mundo Pós-Produzido: "o cidadão do espaço público internacional", "universalmente exótico" - podendo assumir diferentes identidades, as quais se manifestam de forma dinâmica e mutante, como se observa em obras de Rirkrit Tiravanija (BOURRIAUD, 2009). De certa forma, Dautremer também se utiliza de características do homem mutante por meio de personagens tão diversificados que impossibilitam identificar 
quais seriam suas possíveis origens, o que leva a entender que poderiam ser de qualquer lugar (Figura 10, 11 e 12). Suas vestimentas também variam de medievais a contemporâneas, de ocidentais à orientais, de reais a ficcionais. Da mesma forma, os cenários criados misturam traços de cidades modernas com vilarejos antigos, ora contando sobre o passado, ora falando do contemporâneo, todos parte de uma mesma história num tempo presente para os personagens.

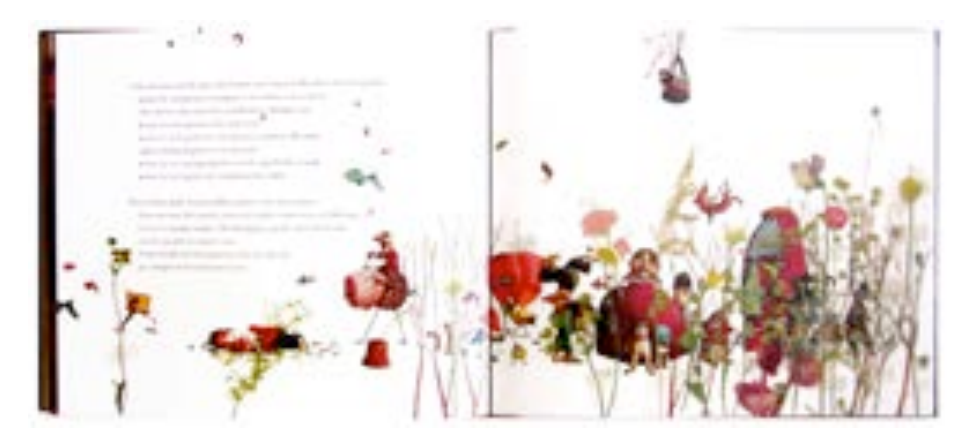

Figure 12: Páginas 68 e 69 do Diario Segreto di Pollicino (LECHERMEIER, 2010)

Retomando a relação entre o real e o imaginário, para Bourriaud a Pós-Produção permite que a ficção e a realidade misturem-se pacificamente, questionando seus próprios limites. A ficção expõe a realidade ao passo que a realidade zomba da fiç̧ão. Daí a necessidade de se mostrar a possibilidade de novos enredos ao mundo que já está criado. $\mathrm{O}$ artista Pierre Joseph, ao defender o uso de personagens de quadrinhos e contos de fadas em sua obra, diz que "eles não nos convidam a fugir da realidade; pelo contrário, essas imagens que fazem a aprendizagem do real" (BOURRIAUD, 2009, p. 77). É nesse encontro entre a ficção e o real que a intervenção humana se manifesta na tela "Zorro" de Mauricio Cattelan (1993). A tela, rasgada três vezes em forma de "z", remete ao personagem de ficção Zorro, criado em 1919 pelo escritor norte-americano Johnston McCulley. Zorro, um transgressor e justiceiro, sai da ficção e deixa suas marcas no mundo real, marcando sua existência e mostrando que nenhuma imagem deve ser intocável. Essa transgressão também é observada na obra Edizioni dell'Obligo (1991) do mesmo artista, obra na qual livros escolares têm sua "capa e título modificados por crianças, numa espécie de desforra e gozação contra todos os programas", como num ato de "delinquência" (Ibid., p. 72).

Se observarmos a capa do livro Diario Segreto di Pollicino (Figura 13) também lá encontramos sinais claros de transgressão, numa manifestação de descontentamento do personagem com os paradigmas do livro. Pollicino não admite que seu Diário seja escrito 
por outra pessoa, pois afinal, é o Diário de Pollicino. Assim, o personagem risca o nome dos autores e coloca sobre eles seu próprio nome. Outro sinal de transgressão pode ser observado na ilustração rasgada e rasurada da capa. Tal fato poderia não ser admitido em um livro, principalmente em uma capa; para muitos tal ato poderia significar um verdadeiro sacrilégio, afinal, livros não devem ser riscados e muito menos rasgados. Seu lugar são as estantes, protegidos com o máximo cuidado, mesmo que isso signifique não manuseá-los. Entretanto, Dautremer se permite rasgar a capa de seu livro e autoriza seu personagem a rasurá-la, numa contravenção que mistura o real e o ficcional.

Também nas folhas de guarda do livro Dautremer autoriza a interferência e novamente a transgressão no espaço atribuído à apresentação dos autores, a qual, geralmente acontece de maneira formal. Nesta obra suas fotografias são rasgadas e misturadas a desenhos, como que numa brincadeira e zombaria infantil. Acompanham insetos colados sobre as folhas com fitas adesivas transparentes. Talvez seja novamente Pollicino quem está brincando com os autores, transformando-os em personagens e caricaturas do mundo real, enquanto ele assume o papel de autor e afirma sua existência. Assim como nas obras da Pós-Produção a autoria é questionada, misturando-se os autores a sua obra. "Os artistas da Pós-Produção não estabeleceram uma diferença de natureza entre seus trabalhos e os trabalhos dos outros, nem entre seus gestos e os gestos dos observadores." (BOURRIAUD, 2009, p. 51). É assim que Dautremer e Pollicino se confundem, tornando também o leitor cúmplice de seus aventuras, pois dividem com ele seu diário secreto.
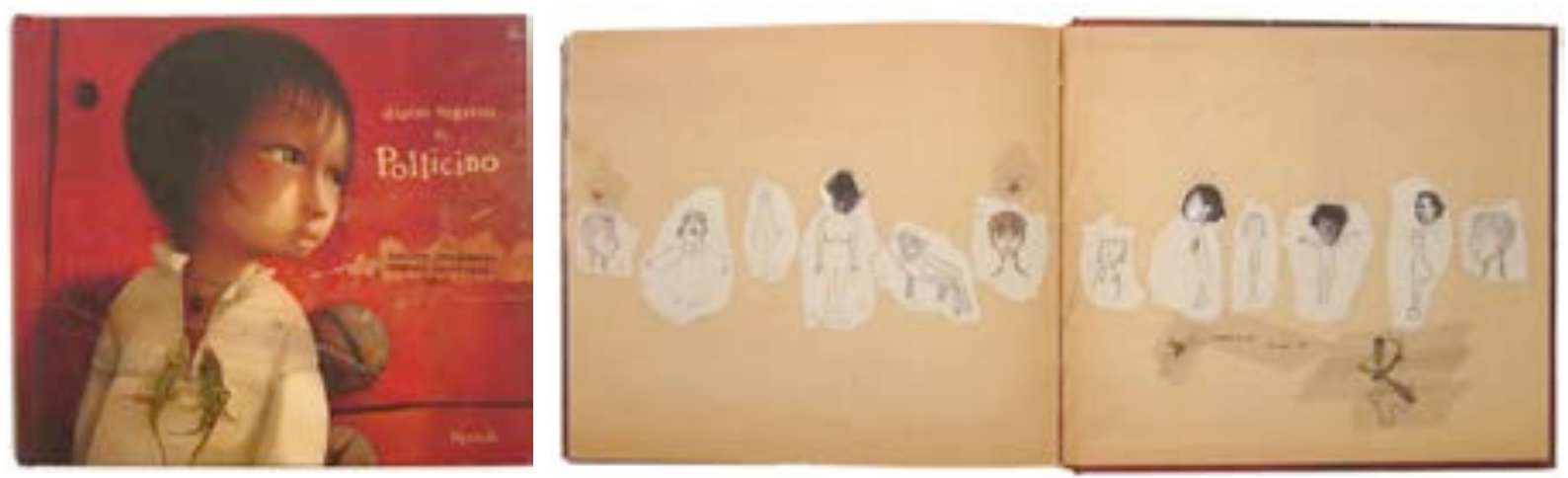

Figure 13: Capa do Diario Segreto di Pollicino (LECHERMEIER, 2010)

Figura 14: Folhas de guarda do Diario Segreto di Pollicino (Ibid.)

Por fim, é perceptível que mesmo uma breve análise das ilustrações pôde despertar para diversas possibilidades de leituras, em uma "teia de elementos", como mencionada por 
Ramalho e Oliveira (2005, p. 53) (2005). Muitos outros aspectos destas imagens poderiam ser também analisados como cores, formas, composição, ritmo visual e articulação entre texto visual e texto verbal ${ }^{9}$, entre outros, proporcionando à leitura outras dimensões. Cabe aos educadores e leitores reconhecer essas possibilidades, não restringindo-se a leitura superficial das imagens, adentrando a suas diferentes camadas de sentidos.

\section{Considerações Finais}

Esse artigo apresentou uma proposta de leitura de imagens do livro ilustrado associada à leitura de manifestações artísticas, que pode ser utilizada na escola, despertando o aluno para o exercício da leitura visual crítica em seus diferentes suportes. Para tanto, foi utilizado como instrumento de leitura o modelo desenvolvido por Ramalho e Oliveira (2005), aplicado a breve exercício, no qual foram analisadas ilustrações do livro Diario Segreto di Pollicino (2010), de Rébecca Dautremer, a partir da perspectiva da Arte na Pós-Produção (Bourriaud, 2009).

A partir desse exercício foi possível observar diversas possibilidades de leituras visuais a serem realizadas em sala da aula de forma a provocar o aluno a alcançar níveis mais profundos e complexos de significações, contribuindo com sua formação visual. Essa formação, que deve estar presente na escola, não envolve apenas o livro ilustrado ou as manifestações artísticas; ela permite que um repertório visual seja elaborado, servindo de base para tantas outras leituras. Acredita-se que a leitura crítica das imagens pode auxiliar na formação de cidadãos mais conscientes de suas escolhas, tornando-os mais exigentes frente as possibilidades do mundo que os cercam.

\section{Referências}

ARIĖS, Phillipe. História Social da criança e da família. 2. ed. Rio de Janeiro: J. Zahar, 1981.

ANDERSEN, Hans Christian. Contos e histórias: Hans Christian Andersen; introdução, seleção, tradução, notas e apêndice de Renata Maria Parreira Cordeiro. 2. ed. São Paulo: Landy Editora, 2004.

\footnotetext{
${ }^{9}$ Em uma publicação recente Nikolajeva e Scott (2011) apresentam uma visão ampla de diversos estudos a cerca do livro ilustrado, utilizando para isso uma abordagem semiótica com especial enfoque na articulação entre texto e imagem. Na mesma obra as autoras esmiúçam os elementos compositivos e narrativos do livro ilustrado, propondo tipologias e ferramentas para análises de palavra-imagem.
} 
BALDASSARRO, R. Wolf. Banned Books Awareness: Where the Wild Things Are by Maurice Sendak. 2011. Disponível em: <http://bannedbooks.world.edu/2011/04/10/banned-books-awarenesswild-maurice-sendak/> Acesso em 30 nov. 2013.

BOURRIAUD, Nicolas. Pós-Produção: como a arte reprograma o mundo contemporâneo. São Paulo: Martins, 2009.

CADILHAC, Julie. Entrevista DAUTREMER, Rébecca. Rébecca Dautremer: the perfection of line and illustration. BSC News. Entrevista. Feb. 17 de 2010. Disponível em:<http://bscnews.fr/20100217768/Bavardages/rebecca-dautremer-la-perfection-du-trait-et-delillustration.html> Acesso em 30 nov. 2013.

CALVINO, Italo. Seis propostas para o próximo milênio: lições americanas. São Paulo: Cia das Letras, 1990.

DAUTREMER, Rébecca. Rébecca Dautremer: uma ilustradora excepcional. Revista Emília Online. out. 2011. Disponivel em:< http://www.revistaemilia.com.br/mostra.php?id=64> Acesso em 20 jul. 2013. Entrevista.

DAUTREMER, Rébecca. Melancolia na tinta de Rébecca Dautremer. Revista Continente online. Artes Visuais. mar. 2013. Disponível em: < http://www.revistacontinente.com.br/index.php/component/content/article/54-artes-visuais/7978rebecca-dautremer.html> Acesso em 20 jul. 2013. Entrevista.

LECHERMEIER, Philippe; DAUTREMER, Rébecca (ilustração). Diario segreto di Pollicino. Milano: Rizzoli, 2010.

LINDEN, Sophie van der. Para ler o livro ilustrado. São Paulo: Cosac Naify, 2011a.

LINDEN, Sophie van der. Para ler o livro ilustrado. Abr. 2011b. Disponível em: <http://editora.cosacnaify.com.br/ObraEntrevista/11359/89/Para-ler-o-livro-ilustrado.aspx> Acesso em: 30 nov. 2013. Entrevista.

LINS, Guto. Livro Infantil? Projeto gráfico, Metodologia, Subjetividade. 2. ed. São Paulo: Rosari, 2003.

DAUTREMER, Rébecca. Rébecca Dautremer: Artbook. Paris: Le Chêne, 2009.

RAMALHO e OLIVEIRA, S. R. Leitura de Imagens para a Educação. 1998. 288f. Tese (Doutorado em Comunicação e Semiótica) - Programa de Estudos Pós-Graduados em Comunicação e Semiótica, PUC/SP. São Paulo, 1998.

Imagem também se lê. São Paulo: Edições Rosari, 2005.

SCOTT, Carole; NIKOLAJEVA, Maria. Livro ilustrado: palavras e imagens. São Paulo: Cosac Naify, 2011.

ZIMMERMANN, A., RAMALHO e OLIVEIRA, S. R. E. llustrações de livros infantis no ensino de artes. In: XVI Encontro da Associação Nacional de Pesquisadores em Artes Plásticas, 2007. I Congresso Educação, Arte e Cultura, 2007.

ZIMMERMANN, Anelise. As ilustrações de livros infantis: o ilustrador, a criança e a cultura. 2008. 148 p. Dissertação (Mestrado em Artes Visuais) - Programa de Pós-Graduação em Artes Visuais, CEART/UDESC. Florianópolis, 2008. 